\title{
Rede de atores da Educação Física no Rio Grande do Sul: o caso do professor Frederico Guilherme Gaelzer
}

https://doi.org/10.11606/issn.1981-4690.ی35i2p293-303

\author{
Paulo Renato Vicari* \\ Vanessa Bellani Lyra*/** \\ J anice $\mathrm{Mazo}^{* / * * * *}$
}

*Universidade Federal do Rio Grande do Sul, Porto Alegre, RS, Brasil.

**Universidade de Caxias do Sul, Caxias do Sul, RS, Brasil.

***Universidade do Porto, Porto, Portugal.

\section{Resumo}

Os estudos sobre o professor Frederico Guilherme Gaelzer destacaram, sobretudo, sua atuação na recreação pública, em Porto Alegre. Tais pesquisas, ao lançarem luzes sobre sua participação em alguns setores educacionais, pouco aludem sobre seu empenho no desenvolvimento da Educação Física nas escolas. Em razão disso, a presente pesquisa trata de investigar como ocorreu a atuação do professor Frederico Guilherme Gaelzer no cenário da Educação Física escolar sul-rio-grandense. Para fins deste estudo histórico-documental, além da revisão bibliográfica sobre o tema procedeu-se a análise de documentos. As fontes analisadas revelaram que Gaelzer sensibilizou o poder público de Porto Alegre sobre a importância da recreação e do esporte para os jovens, coordenando ações voltadas a oferta de práticas esportivas e competições no ambiente escolar e não-escolar, como as praças de Porto Alegre. Quanto a sua contribuição à Educação Física no Estado, podemos destacar a participação na organização dos primeiros Cursos Intensivos, os quais visavam a formação das professoras normalistas. Também foi professor da primeira instituição de ensino superior do Rio Grande do Sul voltada à formação de professoras (es) de Educação Física: a Escola Superior de Educação Física (ESEF).

Palavras-chave: História da Educação Física; Escola; Formação de professoras.

\section{Introdução}

Frederico Guilherme Gaelzer, natural de Novo Hamburgo, então município de São Leopoldo, no Rio Grande do Sul, nasceu em 29 de julho de 1897. Cabe mencionar que já nasceu em uma família de pioneiros, pois seu avô, Coronel Gaelzer Netto, foi intendente de São Leopoldo e ficou conhecido por desenvolver a infraestrutura da cidade em diferentes âmbitos. No mesmo caminho de seu avô e pai, que também era empenhado com o crescimento dos clubes da cidade, o professor Gaelzer teve uma atuação destacada no campo do Esporte e da Educação Física até o seu falecimento no dia primeiro de setembro de 1972, devido a uma embolia pulmonar.

VICARI ${ }^{1}$ aponta que como forma de reconhecimento pelo papel desempenhado, o professor Gaelzer recebeu diversas homenagens, cartôes de agradecimento de ex-alunos e instituições como a Young Men's Christian Association (Y.M.C.A.) de Montevidéu. O seu nome foi conferido ao Centro Natatório da Escola de Educação Física da Universidade Federal do Rio Grande do Sul, onde atuou durante décadas. Ao mesmo tempo em que fora lembrado ao nomear uma rua no Bairro Jardim Salso, em Porto Alegre, onde atualmente fica localizada a Escola Estadual Fernando Gomes.

Frederico Guilherme Gaelzer $\left({ }^{*} 1897+1972\right)$ é destacado nos estudos históricos da Educação Física ${ }^{2-4}$ e nas pesquisas em História do Esporte ${ }^{5}$, sobretudo, por seu pioneirismo na área da recreação pública. Contudo, as referidas pesquisas pouco aludem a atuação do professor Gaelzer no desenvolvimento da Educaçáo Física nas escolas, espaço este ao qual muito contribuiu para sua efetiva estruturação. 
As memórias acerca do envolvimento do professor Gaelzer na escolarização da Educação Física sul-riograndense foram negligenciadas.

Nesse sentido, a pesquisa trata de investigar como ocorreu a atuação do professor Frederico Guilherme Gaelzer no cenário da Educação Física escolar sulrio-grandense.

O presente estudo preocupa-se em contribuir com a (re)construção da trajetória educacional do campo da Educação Física sul-rio-grandense, na medida em

\section{Método}

Este estudo caracteriza-se por apresentar uma abordagem histórico-documental, pois foi realizado tendo por método a análise de documentos, além da revisão bibliográfica sobre o tema. Nesse sentido, a opçâo metodológica adotada para o tratamento das fontes documentais foi a análise crítica de documentos. A "análise documental busca identificar informaçóes factuais nos documentos a partir de questôes ou hipóteses de interesse" ${ }^{6}$.

A análise documental seguiu os procedimentos recomendados por BACELLAR ${ }^{7}$, que são: fichamento, análise e cruzamento das fontes. Após o de fichamento das fontes, que consiste na elaboração de uma ficha com dados de localização e referência de cada fonte, iniciou-se a etapa de análise. Neste estágio foi feito um processo de codificação, interpretação e de inferências sobre as informaçóes contidas nas fontes, desvelando seu conteúdo manifesto e latente.

Desta forma, por meio da análise documental ${ }^{7}$, as informaçóes foram categorizadas, originando eixos temáticos norteadores da pesquisa. Neste procedimento, a contextualização do documento éfundamental. Devese considerar que o texto foi escrito em um determinado tempo, em outra conjuntura, e por uma determinada pessoa que, ao escrever, traz consigo crenças, valores e opiniốes, que muitas vezes estão anotadas nas

\section{Resultados e Discussão}

\section{Gaelzer e a Associaçáo Cristã de Moços: o início de uma trajetória}

É em sua formação escolar e acadêmica, que as escolhas de Gaelzer tornam visíveis sua crença no que procura (re)posicionar na trama histórica, um de seus principais atores já vistos no cenário em debate. Em outras palavras, pode-se afirmar que já se demorava a hora em que o professor Gaelzer seria abordado como objeto de análise histórica no rol das pesquisas acadêmicas. A pesquisa sobre Gaelzer vem justamente ao encontro do preenchimento de uma lacuna historiográfica para ampliar a compreensáo de como se constituiu historicamente o campo da Educação Física no Rio Grande do Sul.

entrelinhas do documento. Posteriormente, na última etapa, realizou-se o procedimento de cruzamento das informaçôes, no qual foram construídas relaçôes entre as informaçôes para corroborar uma determinada versão ou fazer um contraponto a essa, sempre tendo a atençáo de relacionar texto e contexto.

Para a realização deste estudo, a documentação selecionada e transformada em fonte de informação histórica consistiu em livros, jornais, artigos científicos, monografias, dissertaçóes, teses, Atlas do Esporte no Rio Grande do Sul e o Banco de dados das associaçôes esportivas e de Educação Física de Porto Alegre/Rio Grande do Sul (1867-1945). De outro modo, o grupo das fontes documentais a que fizemos uso definiu-se pelos decretos-lei, relatórios do Serviço de Recreação Pública de Porto Alegre e cadernos contendo recortes de jornais e anotaçóes, estas produzidas e preservadas no tempo pelo próprio professor Gaelzer.

Diante do exposto e, para o alcance do objetivo investigativo anunciado, o presente estudo está organizado nas seguintes estruturas textuais que seguem: "Gaelzer e a Associação Cristã de Moços: o início de uma trajetória"; "A volta ao Brasil: açóes pioneiras para a Educação Física sul-rio-grandense"; "A sistematização da formação de professores" e, por fim, "Educaçáo Física e 'Brasilidade’ no Rio Grande do Sul".

poder edificante que atribui à Educação Física. Sua formação escolar foi bastante diversificada, iniciandose em 1910, quando cursou a escola primária em São Leopoldo. Após a conclusão desse curso foi para Berlim, na Alemanha, em 1913, onde fez o curso secundário. 
Anos depois, quando retornou da Alemanha, começou a praticar natação na Associação Cristã de Moços (ACM), em Porto Alegre, no ano de 1918. No ano seguinte, em 1919, viajou para os Estados Unidos, convidado pela ACM, permanecendo em Nova York no período de 5 a 12 de junho e, posteriormente deslocou-se para o Campo de Verão da Young Men's Christian Association (Y.M.C.A.), no George Williams College, em Illinois. Ainda, nos Estados Unidos, cursou Educação Física na Universidade de Chicago, recebendo o título de Master of Science em Educação Física e Recreação, no ano de 1921.

Logo após a formatura, ainda no ano de 1921, o professor Gaelzer foi atuar no México, enviado pela ACM. No ano seguinte, retornou para trabalhar em Chicago, como professor do Y.M.C.A. Hyde Park. Neste mesmo ano, 1922, participou de concurso público para professor de ensino superior na área de Educação Física na Flórida, sendo nomeado para trabalhar nas escolas de Dania, Fort Lauderdale e Miami. No ano seguinte, em 1923, voltou ao Brasil, mas permaneceu pouco tempo em Porto Alegre, deslocando-se para a ACM de Montevidéu no Uruguai, onde trabalhou com basquetebol e participou dos programas de recreação pública. No ano seguinte, retornou a Porto Alegre, onde posteriormente iniciou sua atuação na recreaçáo pública.

\section{A volta ao Brasil: açóes pioneiras para a Educaçáo Física sul-rio-grandense}

Em um exercício de volta no tempo histórico, nos deparamos com o registro do ano de 1877 , no qual ocorreu a inclusão da Educação Física no currículo da Escola Normal de Instrução Primária de Porto Alegre $^{8}$. No entanto, as fontes analisadas nos levaram a constatar que ainda em 1890, a Educação Física nas escolas de ensino fundamental do Rio Grande do Sul era praticamente inexistente. Em linhas gerais, esse primeiro momento caracterizou-se por uma inclusão meramente descritiva da disciplina, nas dimensóes do currículo formal.

Novas leis e direcionamentos relacionados a esta disciplina começaram a surgir posteriormente, mas nenhum fora capaz de regulamentar, de fato, o espaço, o tempo e a quem caberia a responsabilidade pelo ensino dos conteúdos. Dessa forma, percebe-se que a Educação Física, na época, era uma disciplina lecionada pelos professores de classe não possuindo caráter científico nem profissional. Talvez, devido ao fato de não existir instituições profissionais que preparassem professores especializados para atuarem nas escolas elementares do Estado.

Os registros históricos nos apontam que, aproximadamente até o ano de 1929, os professores preparavam suas sessões de Educação Física através de leituras de livros disponíveis sobre ginástica, que geralmente eram oriundos de um país estrangeiro. Havia alguns professores que eram afiliados a Turnerbund de Porto Alegre, posteriormente, denominada "Sociedade de Ginástica Porto Alegre, 1867” (SOGIPA), onde a ginástica alemã era ensinada? .

Nesse mesmo ano, no dia 21 de janeiro de 1929, é promulgado o Decreto Estadual no. 4.258, o qual transferiu a administração da instrução pública estadual da Secretaria do Interior para à Diretoria Geral da Instrução Pública. Tal Diretoria, subordinada à Secretaria do Interior, tinha o objetivo de administrar, articular, orientar e, também, fiscalizar o ensino ministrado nas escolas mantidas pelo governo do Estado. Tal documento foi inserido na legislaçáo educacional do Estado a partir da autorização do entâo presidente do Rio Grande do Sul, Getúlio Vargas.

Talvez este último aspecto, o da fiscalização do ensino, mereça ser destacado como a peça propulsora deste sentido de inauguraçáo trazido pela criaçáo da nova Diretoria. Além da proposição de uma nova política de formação profissional já anunciada nos documentos anteriores, a inspeção do trabalho pedagógico realizado passou a ser considerada uma medida fundamental aos êxitos do processo no cenário educacional do Estado, em termos de sua consolidação nas escolas. Afinal, as novas concepçóes que passaram a ser adotadas para o campo da Educação sul-rio-grandense certamente não ficaram livres de críticas, disputas e resistências por parte daqueles que há tempos atuavam no magistério e que, por vezes, já estavam habituados com os seus próprios conceitos de Educação e seus modos de fazê-la. Fiscalizar o trabalho docente, nesse sentido, passou a ser considerada parte do processo de implantação de um novo conceito de educação, que se pretendia hegemônico nas escolas públicas primárias do Rio Grande do Sul.

Sob as ordens de um Diretor Geral, cargo que neste momento era ocupado pelo juiz da comarca de Bento Gonçalves, o bacharel Luiz Freitas e Castro (Decreto n. 4.131, de 31 de agosto de 1928) ${ }^{10}$, a Diretoria subdividia-se em três sessóes: a Seção Administrativa, a Seçáo Técnica e o Almoxarifado. Nesse arranjo, a estrutura que mais interessou nesse 
momento é a Seção Técnica, cuja organização de pessoal se fazia pelas figuras dos inspetores de ensino, responsáveis diretos pela supracitada fiscalização.

A Educação Física, incluída na Seção Técnica da Diretoria Geral, era supervisionada por um inspetor especialmente designado para o cargo. A Inspetoria de Educação Física tinha como finalidade centralizar a Educação Física no que tange à administração, elaboração de programas e supervisão desta disciplina nas escolas estaduais do Rio Grande do Sul.

Mesmo que seu espaço e reconhecimento ainda estivessem em construção, há evidências de que a Educação Física passou a ser compreendida como um elemento importante no contexto escolar sulrio-grandense. Não obstante o aumento gradativo de carga-horária nos currículos das escolas elementares e dos cursos de formação profissional, a criação de uma inspetoria com vistas a vigiar o trabalho que era desenvolvido no interior da disciplina de Educação Física revela, entre outras, a preocupação em consolidar, no ambiente escolar, um saber particular que se tornava significativo e, ao mesmo tempo, transmiti-lo adiante com eficácia e eficiência.

Mas, em termos práticos, emergiu a dúvida sobre as atribuiçóes do inspetor de Educação Física. Assim como aos demais cargos de fiscalização criados pelo decreto de 1929, ao referido inspetor pontuou-se competências que deveriam ser postas a feito pelo nomeado ao cargo. Essas foram trazidas à tona no artigo 18 do supracitado decreto: apresentar anualmente ao Diretor Geral um programa de Educação Física; desenvolver e executar o programa; orientar os professores e inspecionar as escolas; organizar o escotismo nas escolas; propor a aquisição de aparelhos e materiais apropriados à Educação Física ${ }^{11}$. Além de tais encargos, o inspetor deveria elaborar um relatório anual das atividades e apresentar ao Diretor Geral, até o dia 15 de janeiro do ano seguinte.

A criação de uma inspetoria com vistas a vigiar o trabalho que era desenvolvido no interior da disciplina de Educação Física revela, entre outras, a preocupação em consolidar, no ambiente escolar, um saber particular que se tornava significativo e, ao mesmo tempo, transmiti-lo adiante com eficácia e eficiência. Vale lembrar que o professor Gaelzer inaugurou o cargo de Inspetor de Educação Física no estado sul-rio-grandense. Muito procurado pelos jornais locais da época, o referido professor lançava-se pacientemente ao trabalho de receber os jornalistas em seu gabinete e, a partir de longas reportagens, educar a população para um novo olhar sobre o papel da Educação Física na sociedade.

Mesmo que seu espaço e reconhecimento ainda estivessem em construção, há evidências de que a Educação Física começava a ser compreendida como um elemento proeminente no contexto escolar sul-rio-grandense. Ainda em março de 1929, ocorreu a promulgação do Decreto Estadual $\mathrm{n}^{\circ}$. 4.277, que regulamentou o ensino normal e complementar. $\mathrm{O}$ ensino normal era ministrado na Escola Normal de Porto Alegre e em escolas complementares localizadas na capital e em outras cidades do Estado.

A Escola Normal, cujo programa de estudos era de dois anos, após a aluna(o) cumprir três anos de educação complementar, incluía sessões de Educação Física no currículo escolar com duração de 50 minutos cada uma ${ }^{12}$. Um mês após a promulgação do referido decreto estadual, em abril de 1929, a Educação Física é referida como disciplina obrigatória para todos os alunos dos cursos normal e complementar do Estado.

O professor Gaelzer, com o intuito de formular um programa de Educação Física para as escolas complementares do Estado, estabeleceu que as finalidades principais desta disciplina seriam o desenvolvimento físico-pessoal de cada aluno e o fornecimento de conhecimentos básicos para que os futuros professores de ensino fundamental demonstrassem competência no ensino da Educação Física. Este plano determinava que as sessóes de Educação Física fossem diárias para todos os níveis escolares, sendo duas vezes por semana as aulas ministradas em local interno, espaçoso e em lugar arejado. Quanto ao aspecto recreativo das sessóes, seriam realizadas, sempre que fosse possível, ao ar livre.

No que diz respeito aos alunos das escolas complementares do Estado, além de serem instigados a praticar Educação Física vestindo uniformes específicos, eram avaliados quanto à excelência do trabalho, melhoria da postura e assiduidade às aulas. Segundo Gaelzer, as aulas de Educação Física deveriam abranger os seguintes tipos de atividades: a) Jogos e folguedos livres e fiscalizados, inclusive as danças (bailados do folclore); b) Atividades atléticas fiscalizadas e livres; c) Escoteirismo e outras atividades semelhantes, tanto para as meninas como para os meninos; d) Exercícios formais ou ginásticos propriamente ditos; e) Ginástica ortopédica, terapêutica e médica; f) Piqueniques, excursóes e raids escolares; g) Demonstraçóes culturais de postura e ginástica ${ }^{13}$. 
O programa de Educação Física para as escolas complementares foi, provavelmente, a primeira iniciativa com o objetivo de unificar o ensino desta disciplina em todas as escolas complementares do Estado, na década de 1920. O programa elaborado pelo professor Gaelzer apresentava algumas atividades de procedência estrangeira, como por exemplo o newcomb (espécie de jogo introdutório ao voleibol), cageball (jogo pré-esportivo com bola), voleibol e basquetebol. A inclusão de tais atividades nas aulas de Educação Física das escolas complementares do Estado foi certamente influenciada pelo fato de Gaelzer ter permanecido aproximadamente cinco anos nos Estados Unidos, onde tais esportes já se adiantavam na prática.

Os conhecimentos obtidos e as experiências vividas por Gaelzer nos Estados Unidos foram gradativamente aplicados ao ensino da Educação Física no Estado. Percebe-se que havia uma preocupaçáo em instrumentalizar adequadamente o futuro professor de primeiro grau para que pudesse ministrar novas aulas de Educação Física à infância escolarizada. A partir de idéias como essas, o professor Gaelzer foi se destacando e desempenhou um papel decisivo para a estruturação da Educação Física no Rio Grande do Sul.

A preocupação de Gaelzer parecia não se limitar apenas a Educação Física nas escolas, mas também no que diz respeito a organizaçáo da categoria profissional. Nesta direção, fez parte do grupo que fundou a "Associação Rio Grandense dos Professores de Educação Physica” em 1930. Todavia, a organização desta associação tinha o intuito de estabelecer a uniáo do professorado sul-riograndense para que fosse tratado o desenvolvimento da disciplina de Educação Física. Gaelzer assumiu o desafio de se tornar o primeiro presidente da referida entidade e assim, conduzir a construçáo das embrionárias estruturas organizacionais em prol da regulamentação da profissão de "professor de Educação Física”, ainda incipientes no Estado. As atuaçôes de Gaelzer em diferentes funçóes denotam seu compromisso com o campo da Educação Física, mas sem perder de vista a necessidade de investir na formação profissional.

\section{A sistematização da formação de professoras (es)}

O primeiro curso intensivo de Educação Física para professores de ensino fundamental do Estado foi promovido pela iniciativa do professor Gaelzer, que na época, novembro de 1929, ocupava o cargo de inspetor de Educaçáo Física. Este curso teve o apoio da Diretoria Geral da Instrução Pública ${ }^{12}$. O Decreto de 1929 estabelecia a realização de cursos intensivos de férias a serem efetuados nos meses de janeiro e fevereiro na Escola Normal de Porto Alegre com o objetivo de atualizar os professores de ensino fundamental ${ }^{12,13}$.

Os cursos intensivos de férias, na ausência de instituiçôes que formassem professores de Educação Física no Estado, tinham o objetivo de atualizar e preparar professores normalistas e/ou complementarista para ministrarem aulas de Educaçáo Física nas escolas estaduais de primeiro grau (ensino fundamental). Muitas professoras que frequentaram estes cursos foram distribuídas pelo Inspetor de Educação Física da Diretoria Geral de Instrução Pública do Estado entre várias escolas, principalmente aquelas localizadas em Porto Alegre. É interessante destacarmos aqui a massiva presença de mulheres compondo o quadro de alunas em formação, reforçando o quadro de feminização do magistério sul-rio-grandense, táo destacado neste período $^{14}$.

O segundo curso intensivo foi finalizado no dia 28 de março de 1930 por nove professoras. Após a conclusão, foram indicadas pelo Inspetor de Educação Física, o professor Gaelzer, para atuarem nos colégios complementares Paula Soares, Fernando Gomes, Voluntários da Pátria, Souza Lobo, Glória, Partenon, 13 de Maio e Tristeza e na Escola Normal de Porto Alegre ${ }^{15}$.

Já o terceiro Curso Intensivo teve como preocupaçáo disseminar conhecimentos nas mais diversas áreas da Educação Física. $\mathrm{O}$ evento apresentou os seguintes conteúdos: 1) Educaçáo Fisica contemplando História; Metodologia (enfocando divisão de uma aula e exercícios calistênicos) e Filosofia; 2) Corpo Humano contemplando Biografia (evolução); Anatomia (estrutura em geral); Fisiologia (respiração e sistema nervoso); Fisiologia do exercício (efeitos do exercício sobre a respiraçáo, circulaçáo e sistema neuromuscular); Higiene (asseio pessoal, banho, alimentaçáo, descanso, ambiente, a postura, o álcool e o fumo); 3) Organização eAdministração nas escolas (programas horários, pátios, monitores, formação de grupos, times e clubes); nos jardins de recreio (programas de atividades, divisão das idades, concursos de suficiência); nos clubes (organização de uniôes, federações de esportes; jogos organizados como voleibol, basquetebol, hoquei, base e tênis); nos campeonatos (denominados relâmpago, eliminação, e turnos); 4) Recreação Pública nos jardins de recreio (propaganda material plantas, administração); 5) Jogos organizados (livres e em massa); 6) Bailados do folclore; 7) Natação (aprendizado pelo método "confiança", saltos, salvamento e aperfeiçoamento) ${ }^{16}$. 
Percebe-se nos programas escolares de Educação Física do Rio Grande do Sul, uma tendência higienista da Educação Física, isto é, formar homens e mulheres sadios, fortes e dispostos à ação.

A realização dos cursos intensivos fez com que despertasse o interesse de administradores educacionais do Estado pelo ensino da Educação Física nas escolas estaduais de ensino fundamental. A obrigatoriedade do ensino da Educação Física, de fato, não fora implementada na época, devido à falta de professores especializados e de instituiçóes que formassem esses profissionais. Foram os cursos intensivos que deram o primeiro impulso para que a obrigatoriedade da Educação Física nas escolas estaduais de ensino fundamental fosse cumprida.

No começo do ano de 1936, do dia dois de janeiro até o dia 15 de fevereiro, foi realizado mais um Curso Intensivo de Educação Física, ainda sob a responsabilidade do professor Gaelzer. Este curso preparou 21 professores normalistas ou com diploma de Curso Complementar para o ensino da Educação Física nas escolas estaduais de primeiro Grau (ensino fundamental). É importante salientar que havia requisitos que os interessados deveriam preencher antes de serem escolhidos para o curso, entre eles cita-se a idade mímima de 18 anos e máxima de 30 anos e apresentação de diploma de conclusão do curso complementar ou equivalente.

No dia que encerrou o curso intensivo, 15 de fevereiro de 1936, um grupo de professores que frequentaram o Curso, como forma de agradecimento a Gaelzer pelo esforço e dedicação e com o objetivo de demonstrar algumas atividades aprendidas, fizeram uma apresentação de ginástica, jogos e dança. A apresentação ocorreu antes da entrega dos diplomas aos participantes do curso; constava com o seguinte programa: "apresentação com marchas, exercícios livres, jogo de cara e coroa, exercícios com bastôes, bailado Tarantela, exercícios com halteres, jogo de relevo do tacape, bailado As de Ouro, exercícios com tacapes e Jogo do Tacape-ball, parecido com o atual jogo de taco $^{17}$. Estavam presentes no evento autoridades, entre elas, o Secretário dos Negócios da Educação e Saúde Pública do Estado, Otelo Rosa, o Diretor da Instrução Pública, Professor Guerreiro Lima, familiares e amigos dos formandos.

Este foi o último curso intensivo que encontramos registro. Nos anos seguintes, com a instauração do período do Estado Novo (1937-1945) e a segunda Guerra Mundial (1939-1945), a formação de professores(as) Educação Física sofreria mudanças significativas. O Governo Federal, pelo Decreto $\mathrm{n}^{\circ}$
1.212 de 17 de abril de 1939, passou a exigir formação profissional específica para o exercício das profissóes de professor de Educação Física, Técnico Desportivo e Médico Especializado Educação Física e Desportos. Vale ressaltar que o Decreto assinalou a preocupaçáo das autoridades educacionais em fazer com que somente os professores normalistas especializados em Educação Física fossem contratados para ministrarem aulas nas escolas estaduais de primeiro grau, atualmente, de ensino fundamental, no território brasileiro.

Em decorrência de tal legislação, ainda no ano de 1939 foi instalada a Escola Nacional de Educação Física e Desportos (ENEFD) da Universidade do Brasil, atualmente, Universidade Federal do Rio de Janeiro (UFRJ) ${ }^{18}$. A ENEFD foi o modelo através do qual outras instituiçóes de preparação de professores de Educação Física deveriam seguir. Com a criação desta instituição houve necessidade, na época, de se determinar um método de Educação Física a ser seguido pela instituição, o que foi motivo para grandes discussóes. Embora, tenha sido motivo para duras críticas da Associação Brasileira de Educação, não sendo implementado, o Método Francês foi adotado pela ENEFD.

As instituiçóes encarregadas da formação de professores de Educação Física, estabelecidas após a ENEFD, adotaram o Método Francês. $\mathrm{O}$ declínio na utilização do Método Francês foi desecadeado após as autoridades educacionais brasileiras fazerem uma severa revisão dos aspectos anatômicos, fisiológicos e psico $\neg$ lógicos da Educação Física no país. Tal avaliação foi ocasionada pela rendição da Linha Maginot, composta por um milhão de soldados franceses, causando uma decepção mundial ${ }^{19}$.

No Rio Grande do Sul, o Método Francês foi criticado pelas autoridades educacionais. O Inspetor de Educação Física da Diretoria Geral da Instrução Pública do Estado, professor Gaelzer, árduo seguidor do Método Sueco de Ginástica, preconizado por Per Henrik Ling, foi um dos maiores críticos do Método Francês no Estado. O professor Gaelzer, uma personalidade da Educação Física na época, com cursos realizados na Europa, Estados Unidos, Uruguai e até mesmo, na Escola de Joinville-le-Pont, na França, concedeu em 1939, entrevista a um jornal de Porto Alegre expressando seu desejo de que o Método Francês não fosse adotado pela ENEFD. Esta manifestação contrária ao Método Francês ocasionou a demissão do citado professor da Inspetoria de Educação Física do Estado ${ }^{20}$.

Embora, afastado da Inspetoria, o professor Gaelzer continuou envolvido com a Educação Física. No final 
do ano de 1939, quando foi apresentada a proposta de criação do Departamento Estadual de Educação Física, o nome dele constava entre os colaboradores. Juntamente com o Departamento foi viabilizado o projeto de criação da ESEF, por deliberaçẫo do então Secretário de Educação do Estado do Rio Grande do Sul, José Pedro Coelho de Souza, atendendo à determinação do Interventor Federal no Rio Grande do Sul, General Oswaldo Cordeiro de Farias. Para Diretor do Departamento e da ESEF foi nomeado, com licença do Ministro da Guerra, o capitáo Olavo Amaro da Silveira. O núcleo inicial da ESEF era formado pelo Diretor-Fundador e os professores: Waldir Calvet Echart, João Gomes Moreira Filho, Max Herbert Hanke e Frederico Guilherme Gaelzer.

O professor Gaelzer figurou no corpo docente pioneiro da ESEF, que entrou em funcionamento no ano de 1940. A ESEF foi a primeira instituição estabelecida no Rio Grande do Sul com objetivo de formar professores de Educação Física. No princípio oferecia os seguintes cursos: Curso Normal de Educação Física, com duração de um ano e Curso Superior, com duração de dois anos ${ }^{21}$.

Segundo LYRA ${ }^{16}$, Gaelzer atuou como professor auxiliar na disciplina de Desportos Aquáticos, cujo responsável era o segundo tenente Nelson Rocha, e também era o professor responsável pela disciplina de Ginástica de Aparelhos de Pesos e Halteres. Após mais de uma década assumiu o cargo de diretor da ESEF, no período de 28/09/1955 a 24/02/195922. O seu trabalho foi reconhecido pela instituição, pois o professor Gaelzer dá nome ao Centro Natatório da ESEF.

Além disso, o professor Gaelzer também foi um dos fundadores de outra instituição importante para o campo da Educação Física, trata-se da Associação dos Especializados em Educação Física e Desportos do Rio Grande do Sul (AEEFD), atual Associação dos Profissionais de Educação Física do Rio Grande do Sul (APEF-RS). A organizaçăo desta entidade, conforme os registros de LicHT ${ }^{23}$, começou com um movimento, nos meses de agosto e setembro de 1945, de professores da ESEF, liderados por Frederico Guilherme Gaelzer e Jacintho Francisco Targa. Tais professores foram apoiados por Maurício Akcelrud, inspetor federal de Educação Física na época, que defendia a fundação de uma entidade de classe para congregar professores, técnicos e médicos especializados em Educação Física e Desportos do estado do Rio Grande do Sul.

Após alguns meses, no dia 20 de dezembro de 1945 , nas dependências da ESEF, foi realizada uma reuniáo de professores de Educação Física, presidida pelo Diretor, na qual se deliberou pela fundação da AEEFD/RS, bem como pela eleição de sua diretoria provisória. Nesta primeira diretoria, o professor Gaelzer ocupou o cargo de secretário cultural. A entidade era encarregada, entre outros atributos, de assegurar os direitos contidos em lei; promover o intercâmbio entre médicos, professores de Educação Física, técnicos e massagistas esportivos; trabalhar para firmar o conceito dos especializados em Educaçáo Física no meio educacional; além de colaborar com todas as instituiçôes legalmente constituídas no sentido da maior divulgação da Educação Física.

\section{Educação Fúsica e Brasilidade: os Jardins de Recreio e a Semana da Raça}

Após um período no exterior, em 1924, Gaelzer retornou ao Brasil, fixando residência na cidade de Porto Alegre. Depois de dois anos, em 1926, junto à Intendência de Porto Alegre, iniciou uma pesquisa sobre as áreas livres com vistas a um futuro atendimento da população em no âmbito da recreação pública. Nomeado em agosto do mesmo ano, foi designado para trabalhar na Intendência Municipal, criando o "Systema de Jardins de Recreio", nas praças da cidade.

Num movimento de reafirmação dos objetivos nacionais de criação de uma identidade brasileira, afeita aos ares históricos do momento, o Governo do Estado do Rio Grande do Sul cria, a partir do ano de 1929, várias praças públicas destinadas à prática de exercícios físicos pelas crianças e adolescentes, denominadas "Praças de Educação Physica". Os chamados "Jardins de Recreio", nesse contexto, eram espaços criados no interior de tais praças que se destinavam, em especial, à atenção ao público compreendido na faixa etária de três a seis anos. Por serem tais Jardins considerados um complemento à escola, estavam estrategicamente localizados junto aos colégios ou em suas imediaçóes. Como exemplo, citamos os quatro primeiros Jardins de Recreios. O primeiro, situado na Praça General Osorio, fazia frente ao Colegio Fernando Gomes, e distava apenas quatro quadras da antiga Escola Normal, do "Gymnasio Anchieta", do "Colegio do Rosario" e do "Collegio Elementar". O Jardim de Recreio n. 2 localizado na Praça General Pinheiro Machado fica ao lado do Colégio e Seminário Evangélico e a duas quadras do colégio metodista. $\mathrm{O}$ de $\mathrm{n} .3$ que ocupa a Praça Florida ficava ao lado do futuro colégio da cooperativa dos empregados da viação férrea. Já o de n. 4, também denominado Dr. Montaury, estava somente uma quadra do Colégio Nossa Senhora do Bom Conselho, duas quadras do Colégio Espirito do Nazareno e a quatro quadras do Colégio Porto Alegre 
e da Instituição Pia Chaves Barcellos ${ }^{23}$.

Tais espaços eram dotados de brinquedos, campos e piscinas onde, ao exercitarem-se constantemente e de forma lúdica, as crianças estariam robustecendo os músculos e preparando uma "juventude forte, hygida, apta a arrostar as vicissitudes da vida actual" 24 . Importa destacarmos que ambas as iniciativas educacionais foram trazidas ao Rio Grande do Sul pelo professor Gaelzer que, após visitas e estudos em países estrangeiros, da América e da Europa, irradiou ao Estado os modernos conhecimentos que lá adquiriu acerca dos rumos da nova, cientifica e eficiente Educação Física.

Conforme $\mathrm{CunHA}^{3}$, as praças eram vistas como complemento da escola. Desse modo o programa de Educaçáo Física da escola e o da praça obedecia à mesma orientação, e tendo o mesmo fim, foram fundidos num único. As praças mantinham relação intima com a escola. Eram locais espaçosos, que tinham um programa e proporcionavam aos frequentadores alegria pelas práticas de jogos e atividades ao ar livre.

As açóes desempenhadas por Gaelzer na recreação pública em Porto Alegre são equivalentes às cidades como, por exemplo, o Rio de Janeiro, no início do século $\mathrm{XX}^{25}$. São Paulo e Belo Horizonte são outros exemplos de cidades brasileiras com iniciativas de administraçóes municipais direcionadas para a ampliação dos espaços de lazer. É provável que o professor Gaelzer, que sugeriu a instalação de equipamentos para prática esportiva em praças e, por conseguinte a denominação de "Praças de Educação Física/Desportos”, tenha utilizado como modelo o caso das praças de esportes existentes no Uruguai, desde $1913^{26}$.

Porto Alegre é reconhecida como a primeira cidade na criação de um serviço de recreação financiado pelo poder público. Esse reconhecimento se dá a partir da oficialização do Serviço de Recreação Pública em 1926, o qual institucionalizava a aplicação de conteúdos afetos a área da Educaçáo Física e da recreação nas praças, parques, balneários públicos que desenvolviam atividades visando propiciar, aos portoalegrenses, vivências onde experienciavam situaçóes de sociabilidade, lazer, entretenimento e recreação. Nas praças que tinham jardins de recreio, a média de frequência mensal era de " 25.000 de crianças e jovens, distribuídos em turmas ao longo do dia”. Em palestra proferida, Gaelzer afirmou que os Jardins de Recreio "eram frequentados, diariamente, por mais de mil pessoas" ${ }^{1}$. Porto Alegre era uma cidade que comportava aproximadamente 250.000 habitantes, apesar da diminuiçáo do fluxo migratório.

No rol dos espaços de atuação criados por Gaelzer, a presença do professorado se consagrou, também, nos eventos cívicos conhecidos por "Semana da Raça". Guiada pelos mesmos objetivos que motivaram à criação das praças e jardins de recreio, a "Semana da Raça”" constituiu-se numa festividade cívica, também criada pelo governo do Estado, no ano de 1933, na qual a grandeza e a força da "raça brasileira" vinham à tona por meio de demonstraçôes e evoluçôes físicas realizadas por escolares, e pela prática concentrada de exercícios físicos ao longo dos dias que compunham o período estipulado. $\mathrm{O}$ "aprimoramento racial, a formação de um typo ethnico perfeito, bem compleicionado, desenvolto" ${ }^{27}$, encerravam os objetivos principais do evento ${ }^{a}$.

A "Semana da Raça” ou também conhecida por "Semana da Pátria", era uma forma expressiva de manifestaçáo corporal esportiva fomentada pela chegada do regime político do Estado Novo (1937-1945). No ápice desse regime, dentre estas comemoraçóes realizadas as "demonstraçôes de Educação Física" tomam um espaço especial nas festividades. Cabe ressaltar que no mês de setembro de 1928, o professor Gaelzer já tinha organizado a primeira demonstração de Educaçáo Física, um evento no qual as normalistas exibiam exercícios ginásticos, nas comemoraçóes da Semana da Pátria.

Outra maneira de olhar para essas manifestaçôes é como forma de controle social, através do corpo como, por exemplo, as demonstraçóes de Educação Física, que culminavam em festas cívicas. A "Semana da Pátria" é uma festividade que pode ser considerada momentos importantes no lazer do trabalhador que foram utilizados ideologicamente ${ }^{28}$. Nas praças aconteciam festas cívicas nos festejos $\mathrm{da}$ semana da pátria, compostas de provas esportivas e momentos culturais, com apresentaçóes de hinos e declamaçóes de poesias ${ }^{2}$.

Ainda a respeito desse cenário, explica-se que a ocupação das praças e parques nestas festas cívicas aparece inserida neste contexto de progresso e de renovação de mentes pretendidas pelo Estado Novo. A educação corporal e moral da juventude, nas praças, somavam-se ao processo desencadeado nas escolas e associaçôes esportivas visando à formação da nação brasileira. CunHA ${ }^{3}$ complementa que as demonstraçóes de Educação Física na "Semana da Pátria" serviam de mediação de práticas e manutenção de visōes, como meio difusor no imaginário social no período do Estado Novo.

A abordagem histórica do presente estudo, portanto, lançou-se ao desafio de contribuir para o avanço dos estudos afeitos à área da formação de professoras(es), ao 
interpretar a atuação do professor Gaelzer no cenário da Educação Física sul-rio-grandense. A análise das fontes históricas as quais nos debruçamos revelou, na postura desse professor, um protagonismo de açóes, que alocaram a Educação Física do sul do país e na vanguarda do cenário educacional nacional. Todavia, tal protagonismo não significa uma ação individual do professor Gaelzer, mas sim um lugar de destaque em um tempo e espaço, dentre os atores que construíram o campo da Educação Física.

Quanto ao papel desempenhado pelo professor Gaelzer frente à Educação Física, podemos mencionar sua atuação decisiva quanto à formação dos professores dessa área, sendo ele no cargo de Inspetor de Educação Física ou como organizador dos primeiros cursos intensivos dessa disciplina no Estado do Rio Grande do Sul, para professoras primárias. Ainda, podemos lembrar que o professor colaborou, em comissão, no projeto de criação da ESEF, atual Escola de Educação Física, Fisioterapia e Dança (ESEFID) da UFRGS, onde foi professor e diretor. Gaelzer também ajudou a fundar a AEEFD, atual Associação dos Profissionais de Educação Física do Rio Grande do Sul (APEF-RS).

Por meio das praças, os porto-alegrenses se habituaram a ver demonstrações de espírito esportivo exaltado e uma disciplina necessária para um futuro promissor de crianças, de jovens, da pátria, de todos. Elas se vinculavam à ideia da importância do fortalecimento físico, mental e moral dos seus praticantes para o crescimento do Brasil, mesmo pensamento que inspirava Gaelzer em suas açóes. A liderança proveniente do professor Gaelzer, como registravam os jornais da época (Correio do Povo, Diário de Notícias, Folha Esportiva, Jornal do Comércio), foi essencial para a Educação Física conquistar um espaço na escola sul-rio-grandense.

As propostas empreendidas por Gaelzer foram viabilizadas em um cenário que favoreceu suas açôes. Era uma época em que as práticas corporais e esportivas ganhavam impulso por diferentes motivos. Na cidade de Porto Alegre, desde a segunda metade do século XIX, práticas foram institucionalizadas em associaçóes, principalmente organizadas pela iniciativa dos imigrantes alemáes. No começo do século XX houve a disseminação de ideias que valorizavam as práticas esportivas. Vale lembrar que Gaelzer, frequentou clubes, mas, particularmente, teve forte envolvimento com a ACM de Porto Alegre, a qual se sabe interligada a outras no Brasil e articulada com uma rede mais ampla na América Latina, Estados Unidos, outros países, sob a tutela da Y.M.C.A.

Desta forma, pode-se afirmar que havia condiçóes postas para o desenvolvimento da Educação Física e dos esportes nos clubes, escolas e, posteriormente, nas praças públicas. E foi este contexto que, provavelmente, permitiu Gaelzer tornar-se um protagonista. Entretanto, sabese que embora tenha se destacado no campo da Educação Física, do esporte e da recreação pública, conseguiu empreendeu muitas açóes em razáo de colaboradores que, muitas vezes são invizibilizados pelos documentos oficiais, por não ocuparem os cargos principais. Gaelzer, provavelmente contou com uma rede de pessoas como, por exemplo, os membros da comissão de criação da ESEF e os professores desta instituição quando se tornou diretor.

Por fim, espera-se que este estudo contribua para preservar as memórias do processo de escolarização da Educação Física. Todavia, apontamos a necessidade de outros estudos para desvendar os demais atores do campo da Educação Física e do esporte sul-rio-grandenses. 


\begin{abstract}
Physical Education stakeholders network in Rio Grande do Sul: teacher case Frederick William Gaelzer

Studies about teacher Frederico Guilherme Gaelzer, highlighted, above all, his role in public recreation in Porto Alegre. Such research when launching light on his participation in some educational sectors, allude just a little bit about his commitment to the development of physical education in schools. As a result, the present study aims to investigate how was the performance of Professor Frederico Guilherme Gaelzer in school Physical Education setting of Rio Grande do Sul. For purposes of this historical documentary study, in addition to literature review on the topic, a document analysis was also proceeded. The sources analyzed revealed that Gaelzer sensitized the government of Porto Alegre about the importance of recreation and sport for young people, coordinating actions towards the provision of sports practices and competitions at school and non-school, like the squares of Porto Alegre. As his contribution to Physical Education in the state, we can highlight the participation in the organization of the first Intensive Courses, which were aimed at the formation of teachers who attended the old Normal Schools. Gaelzer also taught in the first university of Rio Grande do Sul focused on training Physical Education teachers: School of Physical Education (ESEF).
\end{abstract}

KEYWORDS: History of Physical Education; School; Training of teachers.

\title{
Referências
}

1. Vicari PR. Frederico Guilherme Gaelzer: Protagonista da Educação Física do Rio Grande do Sul [trabalho de conclusão de curso]. Porto Alegre (RS): Universidade Federal do Rio Grande do Sul, Escola de Educaçáo Física, 2013.

2. Feix E. Lazer e cidade na Porto Alegre do início do Século XX: a institucionalização da recreação pública [dissertação]. Porto Alegre (RS): Universidade Federal do Rio Grande do Sul, Escola de Educação Física, 2003.

3. Cunha ML. As práticas corporais e esportivas nas praças e parques públicos da cidade de Porto Alegre (1920-1940) [dissertação]. Porto Alegre (RS): Universidade Federal do Rio Grande do Sul, Escola de Educaçáo Física, 2012.

4. Werneck C. Lazer e Estilo de Vida. Recreação, lazer e estilo de vida no Rio Grande do Sul: refletindo sobre algumas açóes desenvolvidas na capital gaúcha no período 1926-1978. In: Burgos M, Pinto L, organizadores. Santa Cruz do Sul: EDUNISC, 2002. Capítulo 5. p. 88-102.

5. Mazo JZ, Frosi, TO, Silva CF. A Associação Cristã de Moços e a propagação dos esportes em Porto Alegre. Kinesis Santa Maria. 2012;30:158-173.

6. Lüdke M, André, M. A Pesquisa em educação: abordagem qualitativa. São Paulo: EDU, 1986.

7. Bacellar C. Uso e mau uso dos arquivos. In: Pinsky CB, organizador. Fontes Históricas. São Paulo: Contexto, 2010.

8. Coleçâo das Leis e Resoluçôes da Província, 1a Sessão da 17a Legislatura, Tomo 30. Porto Alegre: Tipografia do Jornal do Comércio, 1877. p. 32-33.

9. Lyra V, Mazo J. A Escola Superior de Educação Física e o campo da formação de professores do estado sul-rio-grandense: as origens da formação especializada (1869-1929). Rev Movimento. 2010;16:53-75.

10. Decreto n. 4131, de 31 de agosto de 1928. Porto Alegre: Arquivo Histórico do Rio Grande do Sul [s.n.], 1928. p. 133-143.

11. Decreto n. 4258 de 21 de janeiro 1929. Porto Alegre: Arquivo Histórico do Rio Grande do Sul [s.n.], 1929. p. 46-52.

12. Leis, Decretos e Atos do Governo do Estado -1920. Porto Alegre: Oficinas Gráficas A Federação, 1930. p. 153-154.

13. Gaelzer FG. Correspondência enviada ao Diretor da Instituição Pública do Estado. Porto Alegre, 17 de outubro de 1929.

14. Werle FO. O nacional e o local: ingerência e permeabilidade na educaçáo brasileira. Bragança Paulista: Edusf, 2005.

15. Gaelzer FG. Correspondência enviada ao Diretor da Instituição Pública do Estado. Porto Alegre, 28 de março de 1930.

16. Lyra VB. A Criação da Escola Superior de Educação Física do Rio Grande do Sul: Formaçáo de Professoras(es) para a Construção do Campo (1940-1970) [tese]. Porto Alegre (RS): Universidade Federal do Rio Grande do Sul, Escola de Educação Física, 2013.

17. Cursos de Educação Física. Diário de Notícias. Porto Alegre, 16 de fevereiro de 1936.

18. Melo V. Escola Nacional de Educação Física e Desportos: uma possível história [dissertação]. Campinas (SP): 
Universidade Estadual de Campinas, 1996.

19. Marinho IP. História da Educação Física e dos Desportos no Brasil: Brasil colônia, império e república. Rio de Janeiro: Revista dos Tribunais, 1952.

20. Piccoli JCJ. A Educação Física na escola pública do Rio Grande do Sul: antecedentes históricos (1857-1984). Pelotas: UFPel, 1994.

21. Relatório do General Osvaldo Cordeiro de Farias, Interventor Federal do Rio Grande do Sul, ao Presidente do Estado, Getúlio Dornelles Vargas, durante o período de 1938-1943. Porto Alegre: Oficinas Gráficas da Imprensa Oficial, 1943.

22. Gutierrez W. Diagnóstico das Escolas de Educação Física do Estado do Rio Grande do Sul [dissertação]. Porto Alegre (RS): Universidade Federal do Rio Grande do Sul, Escola de Educação Física, 1976.

23. Licht HFB. Subsídios históricos. Porto Alegre, 2005. p. 1. Disponível em: file://C:/Users/User/Downloads/aeefd.pdf.

24. A Educação Physica: a creação de um curso intensivo. Porto Alegre: Correio do povo, 1929. p. 20-21.

25. Guedes C. 'Changing the cultural landscape': English engineers, American missionaries, and the YMCA bring sports to Brazil - the 1870s to the 1930s. Intern J Hist Sport. 2011;28(17):2594-2608.

26. Dogliotti P. Acerca de la "Cultura Física” en la revista Uruguay-Sport: Archivos de la CNEF, Uruguay (1918-1926). Rev Bras Ciênc Esporte. 2014;36:608-616.

27. Santos A. A Estética Estadonovista: um estudo acerca das principais comemoraçóes oficiais sob o prisma do CineJornal Brasileiro [dissertação]. São Paulo (SP): Universidade Estadual de Campinas, Instituto de Filosofia e Ciências Humanas Campinas, 2004.

28. A Educação Physica no Rio Grande do Sul. Rev Educ Phys. 1937;11:59-61.

\begin{tabular}{r|l} 
ENDEREÇo & \\
Vanessa Bellani Lyra & \\
Universidade Federal do Rio Grande do Sul & Submetido: 11/05/2015 \\
Av. Paulo Gama, 110 & 1a. Revisão: 20/12/2015 \\
96230-000 - Porto Alegre - RS - Brasil & 2a. Revisão: 06/04/2018 \\
E-mail: vblyra@ucs.br & Aceito: 24/05/2021
\end{tabular}

Rev Bras Educ Fís Esporte, (São Paulo) 2021 Abr-J un;35(2):293-303 • 303 